\title{
Research on Talent Policy Changes in Contemporary China
}

\author{
Shenglong Wang \\ School of Economics and Management, Beijing University of Posts and Telecommunications, Beijing, China \\ Email: hi1861@126.com
}

How to cite this paper: Wang, S.L. (2017) Research on Talent Policy Changes in Contemporary China. Open Journal of Business and Management, 5, 550-560. https://doi.org/10.4236/ojbm.2017.53048

Received: June 30, 2017

Accepted: July 25, 2017

Published: July 28, 2017

Copyright (C) 2017 by author and Scientific Research Publishing Inc. This work is licensed under the Creative Commons Attribution International License (CC BY 4.0).

http://creativecommons.org/licenses/by/4.0/

\begin{abstract}
The talent policy in contemporary China has experienced several development periods like restoration and reestablishment, market transformation and strategic propelling, featuring constant evolution with the conflicts and contradictions between its dependence on old path of planned system and its transition into the path suitable for socialist market economic system. Meanwhile, the talent policy in contemporary China is an outcome of the combination between induced system changes and mandatory system changes. The talent policy changes in contemporary China are inherently driven by talent problems, guided by the value of policy community and finally determined by interest differentiation of actors. And the main problems in the changes of talent policy lie in its fragmentation due to lack of systematization and continuity, so it is of top priority to formulate an overall basic talent law.
\end{abstract}

\section{Keywords}

Talent Policy, Changes, Mechanism

\section{Introduction}

Talent policy refers to a series of policies and regulations related to the exertion of talents' ability and function; the regulations, measures and actions taken by the government on the cultivation, development and utilization of talents, mainly including educational policies, employment policies, incentive policies, etc. [1]. Taking the proposal of "Respect Knowledge, Respect Talents" by Deng Xiaoping in 1977 as the historical starting point of talent policy in contemporary China, its development course has gone through over 30 years, during which China's talent policy has witnessed several periods, such as as restoration and reestablishment, reform breakthrough, transformation development and strategic propelling, and now it is in the period of overall development [1]. Based on 
brief analysis of the development processes of talent policy changes in contemporary China, this paper tries to reveal the mechanism of talent policy changes in contemporary China and provide new explanations of China's talent policy. Although the research literature on China's talent policy is rich, most of them focus on introducing the history of talent policy changes, with few involving in the characteristics and mechanism of policy change. Therefore, the main contribution of this paper lies in its conclusion for China's talent policy change characteristics from the perspective of new institutional economics and its discussion on the mechanism of China's talent policy changes from a dynamic angle.

\section{Talent Policy Change History in Contemporary China}

Different scholars may hold different views on period division of China's talent policy changes since the historical starting point of "Respect Knowledge, Respect Talents" proposed by Deng Xiaoping in 1977. Among them, there are two representative ones. The first one is that after the reform and opening-up, based on the development course of economic changes, the history of talent policy changes is divided into 3 periods: reform and opening-up, socialist construction with Chinese characteristics and building a moderately prosperous society in all aspects; while the second one argues to take the issuance of representative talent policy as the turning point, dividing the history of talent policy changes into three periods, restoration and reestablishment period, market transformation period and strategic advancement period. Combining the above two views and considering the needs of analysis, this paper divides the history of China's talent policy changes into the following 4 periods.

\subsection{Restoration and Reestablishment Period}

This period started from the concept of "Respect Knowledge, Respect Talents" proposed by Deng Xiaoping in 1977 and ended with the holding of the Fourteenth National Congress of the CPC in 1992. The mainstream of talent policies of this period lies in bringing order out of chaos, restoring and implementing various intellectual-themed talent policies, and the core of implementing various talent polices is "Respect Knowledge, Respect Talents". The first was to relocate intellectual's attribute and implement various intellectual-themed talent policies. The National Conference on Science and Technology in 1978 reiterated that intellectual is a part of the working class and their status should be restored; in 1984, Decision on the Reform of the Economic System proposed "to take powerful measures to improve intellectual's social status and improve their working conditions and material amenities", "to employ talents of the new generation and forge a grand team of socialist economic management cadres". The second was to restore basic systems like talent cultivation and management, including restoring college entrance examination, sending students to foreign countries, restoring professional titles, etc. In this period, Academic Degrees Regulations was formulated to implement self-taught examination, restore and establish editorial board of teaching materials and enhance teacher training. To cultivate 
scientific and technical talents, Interim Measures for Allowance for Scientific Research was formulated and implemented, exceptionally promoting a batch of young and middle-aged scientific and technical talents, fostering own doctoral students, proactively selecting and sending students with potential to study abroad. The third was to start realizing the flow of talents. The documents such as Provisions on the Rational Flow of Scientific and Technical Personnel, Report on Several Policy Issues Concerning Strengthening the Construction of Scientific and Technology Teams in Remote Areas and Opinions on the Part-time Jobs of Scientific and Technical Personnel had abandoned the regulations of talent flow to guide the rational flow of talents. In 1987, China started to develop talent markets and enacted Provisions on the Administration of Labor and Employment Service Enterprises to create conditions for talent flow. It also carried out optimized combination and contract employment system within enterprises and organizations, to unravel constraint and realize free talent flow, which had helped large numbers of talents find suitable posts.

\subsection{Market Transformation and Development Period}

This period began in 1992 and ended in the late twentieth Century. In 1992, the documents in Fourteenth National Congress of the CPC declared that the goal of Chinese economic reform was to establish socialist market economic system. The confirmation of market direction of the economic system had made all kinds of policies, including talent policies, to advance in the direction of adapting to the socialist market economic system, and had made fostering and developing talent market become the focus of policies. In 1996, the Interim Regulations on the Administration of Talent Market came into force and meanwhile, China's national civil service system was initially established. The Provisional Regulations on State Civil Servants was formally promulgated in 1993, and later on, a series of supporting stipulations on the assessment, recruitment, appointment and rewards of civil servants were successively enacted, basically forming an intensive policy group with Provisional Regulations on State Civil Servants as the benchmark and various supporting stipulations as the assistance. The policy characteristics of this period can be concluded that talents were regarded as the most valuable resource, and a comprehensive view of talents and institutional guarantee were established. In 1995, Talents Project was proposed, which planned to forge a large number of scientists and academic leaders by the end of 20th Century to accelerate the pace of talent growth. In addition, the focus scope of talent policy began to be broadened with local talents, minority talents and talent development in western areas included into policy concern, but most of the document guidance from related state ministries and commissions were out of the sight of the supreme decision-making level of China.

\subsection{Proposal and Propelling Period of Reinvigorating China through Talent Development}

This period started from early 21st Century and terminated in 2014 when the Eighteenth National Congress of the CPC was held. The strategy of Rejuvenating 
China through Talent Development proposed in the early new Century had become one of the three major national strategies, becoming the general principles of various talent policies and thus making talent work shift from the decentralized development period in which human resource work was just viewed as a part of economic, political and science and technology system reform into the integrated propelling period led by the strategy of rejuvenating China through talent development. Decision of CPC Central Committee and the State Council on Further Strengthening Talent Work established the principle of managing talents by the communist party, adhered to the "people-oriented principle and implemented the strategy of rejuvenating China through Talent Development. It also put forward scientific outlook on talents and formed a scientific mechanism of talent selection, training, evaluation and employment, thus establishing a sound talent market system and further improving the incentive and guarantee mechanism of talents. This highest-level talent strategy planning showed the will of the Party and the state plays a guiding role in the talent policy of this period. Besides, talent policy was extended to overseas with a large number of regulations enacted focusing on attracting overseas talents to serve the country and introducing high-notch oversea talents. In addition, in order to response to the development strategies proposed by our nation like Western Development Strategy and Revitalization of Northeast Old Industrial Base Strategy, the construction of talents in Western and Northeast China was paid much attention.

\subsection{Scientific and Overall Development Period}

In this new century and new stage, according to the situation of international talents competition and the requirements of strategy of Rejuvenating China through Talent Development, the future development of China's talent policy will also face with new problems and challenges. In the Report of the Eighteen National Congress of the Party, talent policy is exclusively illustrated in a special part with highly concise language, which was the first time in the history of Congress of Party Representatives and fully embodied CPC's great attention paid to talent work. The thoughts proposed in the Report such as "stick to ideal and faith", "everyone can be talent and everyone shall fully exert their talents", "to implement innovation-driven development strategy" and "talent work should make efforts to understand and follow the laws of talent development" will guide future Chinese talent policy to the following seven trends, that is, development concept will shift from the one-sided talent concept to the scientific view of talents; development goal will shift from creating a big country with talents to rejuvenating China through talent development; development path will shift from neglecting talents utilization to utilization-oriented path; development mechanism will shift from plan-oriented disposition to market-oriented one; development focus will shift from general talent cultivation to the cultivation of innovative scientific and technical talents [2]; development management will shift from traditional mode to scientific one; and development dimension will shift from the development and utilization of domestic talents to that of talents 
at home and abroad [3].

\section{Characteristics of Talent Policy Changes in Contemporary China}

Talent policy changes of contemporary China is accompanied by the transformation from planned economic system to market economic system, so talent policy in contemporary China evolves constantly among the conflicts and contradictions between its dependence on old path of planned system and its transition into the path suitable for socialist market economic system. Meanwhile, China's talent policy changes is the result of the combination of induced system changes and mandatory system changes.

\subsection{Talent Policy Change of Contemporary China Is a Gradual Evolution Process Based on Path Dependence}

The talent policy change of contemporary China is accompanied by the transformation process from planned economic system to market economic system. The original talent policy was made to adapt to the development needs of planned economic system. According to new institutionalism, once a country chooses a certain system, it will follow the path of the system and thus form path dependence due to the self-reinforcing mechanism of the system. It can be seen from the changes of Chinese talent policy that every process of talent policy reform is accompanied by the contradictions between plan and market, centralization and decentralization, control and service [4]. So, it is impossible to thoroughly get rid of the influence of the original system on talent policy in an one-off manner. Therefore, every reform process of China's talent policy is a gradual process with breakthroughs based on the previous old system and policy.

The reason why it is difficult for talent policy to get rid of path dependence is that in order to abandon a rigid, closed, inefficient talent policy under the old system, the established social interest pattern needs to be readjusted, such as the system of professional title reform, the system to reward, assess or dismiss highnotch talents and performance appraisal system, which inevitably involves the interests of different social groups, thus leading to great resistance and difficulties.

\subsection{Talent Policy Changes of Contemporary China Is an Outcome of the Combination of Induced System Changes with Mandatory System Changes}

Induced system change refers to that people spontaneously create new system arrangements to change or replace the existing system arrangements for sake of seeking profitable opportunities, and it is a spontaneous system change carried out when people pursue profitable opportunities generated due to imbalanced systems. Compulsory system change refers to government-led and top-down institutional changes or replacement. Some changes of talent policies, such as civil 
service related system and policy, mainly belong to mandatory system changes; while some, such as policy changes of studying abroad and the flow of talents, are the products of the combination between induced and compulsory systems. Take the free flow of talents as an example. Under the original planned system, all kinds of talents belonged to unit organizations, and they could not flow freely due to the constraint of organizational power. However, with the active growth of various economic entities outside the system, external profit unobtainable from the original system emerged. So some rational individuals actively considered breaking the shackles of the system and took part-time jobs of various forms, changed jobs or even resigned to undertake businesses. Before being clearly confirmed by the CPC, talent markets around the country had achieved great development, showing the characteristics of induced system change. However, the profit-making behaviors of lower social organizations cannot meet the needs of the whole society on talent markets, so objectively speaking, they need mandatory national laws to make a supplement. Besides, the policies formulated to foster and develop talent markets are not baseless, but on the basis of spontaneous individual behaviors or local innovative policies. They are enforced by laws or regulations on behalf of the national will after receiving the acceptance and recognition of the Party and the nation. Talent markets, as an outcome of the combination between induced changes and mandatory changes, march into regularization and institutionalization from non-standard and chaos.

\section{Talent Policy Change Mechanism in Contemporary China}

The changes of talent policy in contemporary China are inherently driven by talent problems, guided by the value of policy community and finally determined by interest differentiation of the actors.

\subsection{Talent Policy Is Inherently Driven by Talent Problems}

The so-called talent problem refers to social conditions in which many people feel dissatisfied about or even could not bear the status quo of talents in the absence of public-powered intervention. Take China for example, there are such talent problems as lack of creativity and loss of high level talents. Therefore, talent problems truly exist, but whether they can draw people's attention, arise policy concern, enter policy agenda and finally lead to policy making heavily depends on how people interpret their connotation based on practical talent problems. A case in point is our policy for overseas talents, at the beginning of reform and opening up, there existed a big gap between China and developed countries in the west in aspects like scientific technology and education, thus how to narrow the gap through sending talents overseas became the major concern of talent policies. For this reason, we adopted policies to expand government-sponsored overseas education and lower the threshold for self-paying studies abroad. Then, with the increase in the number of students studying abroad, talents loss caused by their retention in foreign countries turned prominent and entered the policy agenda. To solve this problem, China placed more emphasis to attract 
overseas students back home. Since the beginning of $21^{\text {st }}$ century, the international competition over talents has become increasingly fierce. How to participate in this competition and earn a place to reverse the disadvantage of developing countries in competition has become the essential concern of China's talent policies. In this condition, China introduced policies like the "One Thousand Talents Plan" and "Distinguished Experts" to promote a flexible flow of overseas talents [4]. Take China's innovative policy as another example. The lack of innovative talents has been a long-standing problem [5]. However, China's talent policy failed to give priority to the demand for innovative talents in spite of the rapid growth in economy over the last three decades since the reform and opening up. With the fading of demographic dividend, the reform has entered a crucial stage in which innovation will become the main driver for economic growth. Hence, talent policy in this period mainly focuses on the cultivation and introduction of innovative talents. These cases indicate that the change of talent policy is inherently driven by talent problems.

\subsection{Talent Policy Change in China Is Guided by the Value of Policy Community}

The theory of policy network began in 1970s and 1980s and has been widely applied to researches concerning public policies. Differentiated from traditional research methods, policy network concerns all forms of formal and informal relations formed between actors over policy process. These relations are structurally different in which interactions among actors will have a large impact on policy making and implementing. China's talent policy network involves a wide range of interest bodies such as the central government, local governments, experts and scholars, relevant media and the target of talent policy. Drawing on the famous Roots Model proposed by a notable English scholar who epitomized the talent network policy, this paper concludes four types of networks formed in the interaction by interest bodies participating Chinese talent policy process directly and indirectly. They are namely policy community, intergovernmental network, issue network and profession network. These interest bodies interact with each other in different forms, thus forming relation networks of different structures based on their difference in the power and resources they hold.

Policy community, according to China's constitutional system, includes the central administrative bureaucracy and legislative bodies, specifically referring to the NPC and its Standing Committee, the State Council and the relevant ministries and commissions under the State Council. Along the process of China's change in talent policies, a considerable number of policy community members have been involved, including the National People's Congress and the state administrative departments like the Ministry of human resources and social security, Ministry of education, and the State Council. All these departments have the right to formulate national talent policies. In the beginning, China's talent policies were made in the planned economy system, which were decided by one or several governmental policy community members, excluding other interest 
bodies from the interaction. Then, as the planned economy system became more and more market-based, the interaction among interest bodies intensified though policy community remained the power center of state administration and control. Its vital place and role in policy formulation and implementation will not change. The changes in talent policy are guided by the value of policy community and each time the latter changes, the former will change in accordance. The direction of the change in talent policy is also guided by the value of policy community [6].

\subsection{Talent Policy Change in China Is Determined by Interest Disputes of Actors}

The intergovernmental network is mainly composed of local governments, local people's congresses and their standing committees, which are the executor and promoter of central policy. In the Chinese talent policy network, though the policy community remains dominant, the autonomy of the intergovernmental network continues to increase. The profession network of talent policy consists of scholars and experts with a unique understanding of their respective fields. With the deepening of reform in Chinese public administration, the profession network has been increasingly involved in Chinese talent policy. At the meantime, the issue network based on certain issue is also exerting expanding influence. The expanding influence of participants and actors leads to more interactions in Chinese talent policy network. And the change of talent policy will invariably influence interests of different interest groups. Then interest differentiation among these interest groups will cause quite a lot of confrontations in the decision-making process of the whole talent policy. With the prominence of diversified interests, it is hard to strike a balance within a short time. If the confrontation grows intense, policy change is likely to occur to ease such confrontation. From the differentiation of interests to the interest confrontation and again to the re-balance of interests, this dynamic process constitutes the change course of China's talent policy. And the interest differentiation is the decisive cause of China's talent policy changes [6].

\section{Problems in Talent Policy Change and Their Countermeasures}

Although the change of talent policy in China is a gradual process, it is neither systematic nor continuous. Instead, it features fragmentation, that is to say the aim, content and process of the policy, which are supposed to be consistent, complete and coordinated have been segmented, causing a systemic state of policy isolation, policy conflict or even policy confrontation [7]. Change of Chinese talent policy is mainly problem-oriented, which means that new talent policies are intended to solve new problems and achieve new objectives related. As a result, there is little correlation between old and new talent policies and how long a policy will last is not identified. It is usually the case that former policies will be replaced by new ones after a certain period. In general, the policy change fails to 
adopt a comprehensive and coordinated framework to integrate its designation and adjustment.

The fragmentation of talent policy changes includes fragmentation among policy resources, fragmentation between policy requirements and their enforcement; fragmentation among different sectors, and fragmentation between the old and the new. In order to address specific policy issues, there must be policy resources to invest. If we want to further solve the problem effectively, we need to integrate policy resources. However, due to the differences in economic development, the needs of specific groups as well as the departmental control of policy resources, there are redundant policies formulated for a single issue, which causes the dispersion of policy resources. It takes scientific policy content, effective enforcement as well as integrity and correspondence between policy requirement and policy implementation to make a good policy. On the one hand, the policy implementation should stick to the core requirements to realize its objective, principle and basic content. On the other hand, a policy should take into consideration the practice and some variations over the policy implementation, bringing flexibility and innovation. However, this does not make an excuse for the policy fragmentation. If core requirements were missed for intended or unintended reason, then the policy implementation will deviate from the right course, leading to fragmentation of policy process [8]. In addition, based on China's division of responsibility and compartmentalization management system, governmental function is closely related to social problems. Hence, the majority of policies tend to be sectoral as a result of sectoral management. Despite that sectoral policies may influence each other, they are segmented from each other from an overall view. Each sector formulates policies according to their own function, which may have an impact on policies by other sectors. In this way, a situation in which sector policies are segmented from each other from an overall perspective will occur. Furthermore, a policy should remain relatively stable in spite of gradual adjustment and amendment. Thus the policy itself is supposed to be scientific while stressing integrity and continuity. A policy changing suddenly is inconsistent with its requirement for stability and gradualness, hurting the benefits the policy targets and the whole society at large.

To address the main problems in talent policy changes, this paper holds that it is urgent to formulate a comprehensive basic law, for example, Talent Law of People's Republic of China. Additionally, China's legal system for talent policies should be improved and perfected through formulation and promulgation of relevant laws, regulations, and implementation details in such aspects as household registration management, immigration, talent market management, talent evaluation, talent security, talent incentives, and social security [9]. With the two approaches combined, a sound legal environment can be created for talent cultivation and introduction, making government's formulation of talent policies institutionalized and normalized and contributing to the continuity and systematization of talent policies. 


\section{Conclusion}

China's talent policy has witnessed several periods, such as restoration and reestablishment, reform breakthrough, transformation development and strategic propelling, and now it is in the period of overall development. Talent policy change of contemporary china is a gradual evolution process based on path dependence, it is an outcome of the combination of induced system changes with mandatory system changes. Talent policy is inherently driven by talent problems, it is guided by the value of policy community and it is determined by interest disputes of actors. Combing China's talent policy changes and analyzing their characteristics and mechanism, on the one hand, are conducive to discovering the problems in the talent policy changes of contemporary China, hence providing certain reference for the formulation of China's future talent policies, and on the other hand, make a certain contribution to the prediction of the change directions of China's future talent policies. Nevertheless, the studies on China's talent policy changes should not be confined to the exploration over change rules. The changes of China's talent policy are based on the established national development strategy, so what a role such changes have played in China's national development strategies at different periods? What influences China's talent policy changes have generated upon China's talent cultivation and introduction? Furthermore, seen from the regional level, China's regional economic development is imbalance, so whether or not there is difference in talent policy changes between different regions? If there are, what influence such differences have exerted upon regional economic development? These questions are the directions to be studied in the future.

\section{References}

[1] Xiao, M.Z. and Han, X. (2009) Review and Analysis of Chinese Talent Policy over the Three Decades since Reform and Opening-Up. Chinese Talent, 1, 12-15. (In Chinese)

[2] Dong, L.J. and Xu, F. (2016) Some Comments and Reflections on the Policy of Chinese Female Sci-Tech Talents. Studies in Science of Science, 34, 178-185. (In Chinese)

[3] Shen, R.H. (2013) Seven Trends Confronting Chinese Talent Policies. China Health Human Resources, 5, 54-57. (In Chinese)

[4] Zheng, D.L. and Zhong, S.H. (2012) Status Quo and Problems of Chinese High Level Talent Policy and Their Countermeasures. Management of Scientific Research, 9 , 130-137. (In Chinese)

[5] Liao, Z.J. and Huang, C. (2017) Study of the Policy on Chinese Scientific and Technological Talents Innovation. Shanghai Economic Review, 3, 17-22. (In Chinese)

[6] Yu, J.L. and Bu, X.H. (2014) An Analysis of Chinese Talent Policy Change in the New Period-From the Perspective of Policy Network. Campus News Paper of Ningxia Party School, 7, 45-48. (In Chinese)

[7] Li, X. (2009) "One Thousand Talents Plan" and the Fragmented Situation of Chinese Talent Policy. Invention and Innovation, 7, 6-7. (in Chinese)

[8] Zheng, B. (2009) The Harm of Chinese Fragmented Social Security System and Ex- 
ploration of Its Fragmentation Impulse. Social Science in Gansu Province, 3, 50-58. (In Chinese)

[9] Lan, Z.Y. and Liu, Y. (2017) Review of American Talent Strategy. Journal of China National School of Administration, 1, 50-55. (In Chinese)

Submit or recommend next manuscript to SCIRP and we will provide best service for you:

Accepting pre-submission inquiries through Email, Facebook, LinkedIn, Twitter, etc. A wide selection of journals (inclusive of 9 subjects, more than 200 journals)

Providing 24-hour high-quality service

User-friendly online submission system

Fair and swift peer-review system

Efficient typesetting and proofreading procedure

Display of the result of downloads and visits, as well as the number of cited articles Maximum dissemination of your research work

Submit your manuscript at: http://papersubmission.scirp.org/

Or contact ojbm@scirp.org 